\title{
THE INFLUENCE OF THE POROUS STRUCTURE OF LOCAL ACTIVATED CARBONS ON THE IMMOBILIZATION OF THE CONGO RED DYE AND VITAMIN $B_{12}$
}

\author{
Țîmbaliuc Nina, Lupaşcu Tudor \\ Institute of Chemistry of the ASM \\ 3 Academiei str., MD 2028, Chişinău, R. Moldova \\ E-mail: timbaliuc_nina@yahoo.com
}

\begin{abstract}
The adsorption properties of activated carbons, obtained from local raw materials (nut shells, peach and plum stones), towards Congo Red and vitamin $B_{12}$ have been studied. The values of adsorption of these markersubstances are in direct correlation with the structural characteristics of the studied samples of activated carbons, in particular, with their mesopore volume.
\end{abstract}

Keywords: activated carbons, adsorption, mesopore volume, Congo Red, vitamin $\mathrm{B}_{12}$

\section{Introduction}

Environmental Protection is now one of the primary problems of mankind as ecological systems can hardly adapt to anthropogenic factors pressure [1,2]. One of the consequences of environmental degradation caused by intensive development of industry, excessive chemical agriculture and food processing industry is the radically worsening health status of the population. These factors are responsible for the considerable increase of diseases and medical conditions of people, increase of exogenous intoxications. Currently are successfully used several methods of detoxification of the body, but one of the simplest and most efficient methods is entherosorption. The most required entherosorbents are those made of activated carbons. A special role in this respect lies with activated charcoal made from fruit stones, nut shells, grape seeds [3-5]. This is due to the fact that morphological structure of nut shells and fruit stones favors the production of activated carbon with high mechanical strength and increased adsorption capacity. Significant adsorption properties of these activated carbons offer wide possibilities for their use [6-8], including in the complex treatment of poisoning and medical conditions to immobilize, neutralize and eliminate toxic substances from the body through different mechanisms (ions exchange or complexation).

The aim of this study was to estimate the adsorption properties of local activated carbon obtained from the waste products of local food industry towards toxic substances with an average molecular weight (MM 500-1500) as oligopeptides, lipopolysaccharides. As test compounds for adsorption were selected Congo Red dye and vitamin B12, substances frequently used as markers in modeling states of intoxication of the human body $[9,10]$.

\section{Materials and methods}

For this research were selected local active carbons obtained from nut shells - CAN-8, peach kernels - CAS23, plum kernels - CAP, considering the further perspective of their use for medicinal purposes, and the industrial activated carbon - BAU. In accordance with the requirements of the modern Pharmacopoeia Monograph, approved for the medicinal carbon Medicas E, heavy metals content shall not exceed $0.001 \%$ (specification for iron content - not more than $0.06 \%$ ), ash residues $-5 \%$ and the amount of substances dissolved in hydrochloric acid solution $-2.5 \%$. To obtain these quality indices of activated carbons, selected samples were treated with $6 \% \mathrm{HCl}$ solution at boiling temperature for 2 hours. Afterwards, the coal was washed with distilled water until a solution $\mathrm{pH}$ of 5 was reached. Finally, the coal was dried in an oven at $110{ }^{\circ} \mathrm{C}$ until a constant mass was reached. The content of heavy metals, ash residues for selected coal samples were determined in the atomic spectroscopy testing laboratory of the Institute of Chemistry. The concentrations of heavy metals, calcination residues and substances dissolved in hydrochloric acid solution were within the requirements of Pharmacopoeia Monograph for all selected coal samples.

The porous structure of investigated activated carbons was determined from nitrogen adsorption-desorption isotherms $\left(\mathrm{N}_{2}, 77 \mathrm{~K}\right)$ obtained using the AUTOSORB-1MP automatic analyzer (Quantachrome, USA).

As a marker substance was used vitamin $B_{12}$ (Cyanocobalamin) with MM 1355.38 c.u. (Figure 1) and Congo Red dye (Panreac Quimica PA, Analytical Reagents \& Fine Chemicals) with MM 696.66 c.u. (Figure 2). 


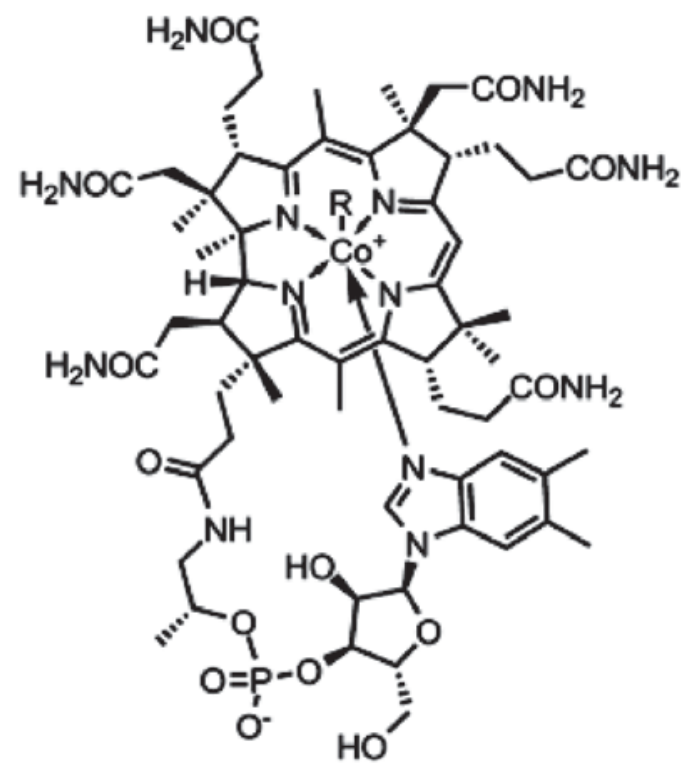

$\mathrm{R}=\mathbf{5}^{\prime}$-deoxyadenosyl, $\mathrm{Me}, \mathrm{OH}, \mathrm{CN}$

Figure 1. Vitamin $\mathrm{B} 12\left(\mathrm{C}_{63} \mathrm{H}_{88} \mathrm{CoN}_{14} \mathrm{O}_{14} \mathrm{P}\right)$

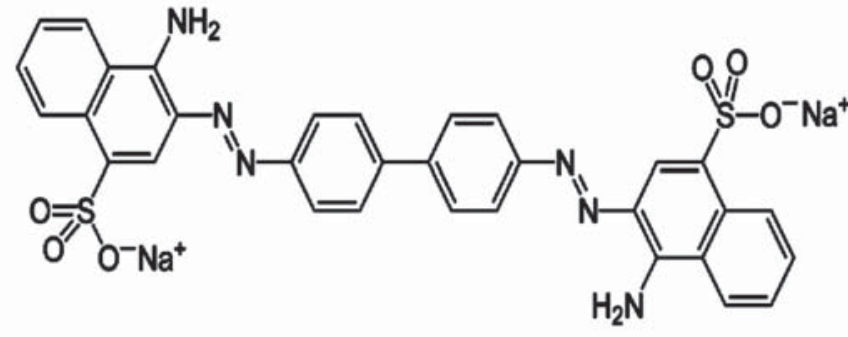

Figure 2. Congo Red dye $\left(\mathrm{C}_{32} \mathrm{H}_{22} \mathrm{~N}_{6} \mathrm{Na}_{2} \mathrm{O}_{6} \mathrm{~S}_{2}\right)$

Adsorption processes were investigated under static conditions. Adsorption isotherms were measured at a temperature of $22^{\circ} \mathrm{C}$, after the process equilibrium was reached. Equilibrium concentrations were determined using the $\mathrm{UV} /$ Vis spectrophotometer, Jenway model 6505. The used experimental method consists in dosing, at known quantities of activated carbon with constant mass $\boldsymbol{m}$ of fixed volume $\boldsymbol{V}$ of solutions with known concentrations $\boldsymbol{C}_{\mathbf{0}}$ and stirring maintained for sufficient time to reach chemical equilibrium at constant temperature.

\section{Results and Discussion}

To assess the immobilizing potential towards studied compounds, structure parameters were determined and adsorption capacity of selected activated carbons. The nitrogen adsorption-desorption isotherms for investigated coal samples are shown in Figure 3.

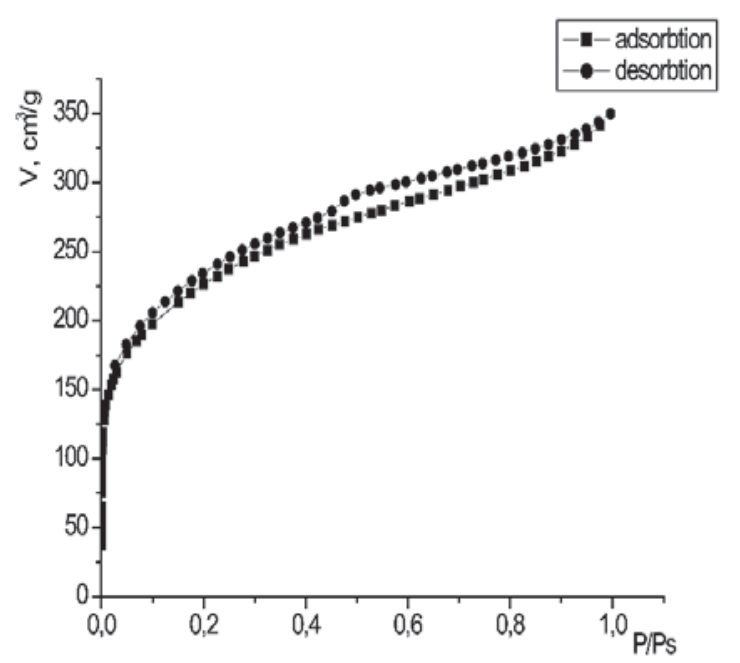

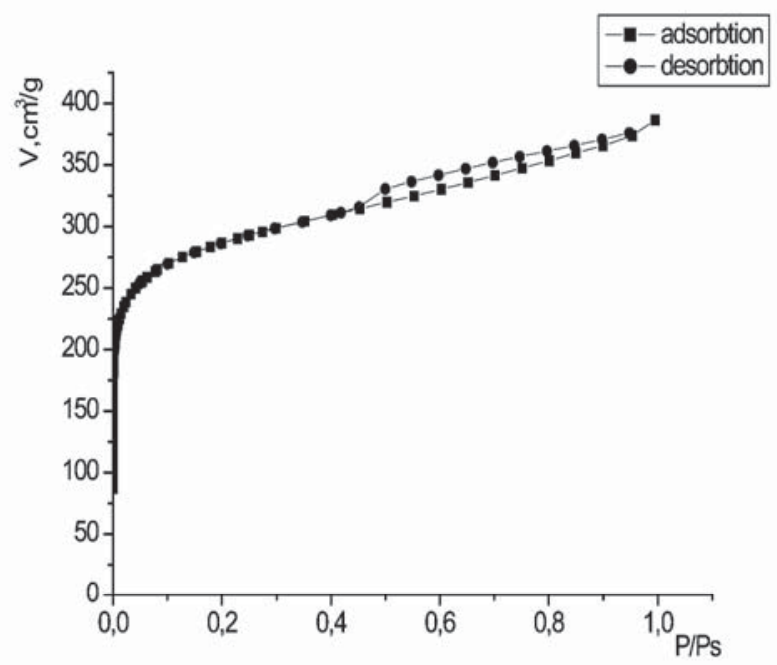

2 


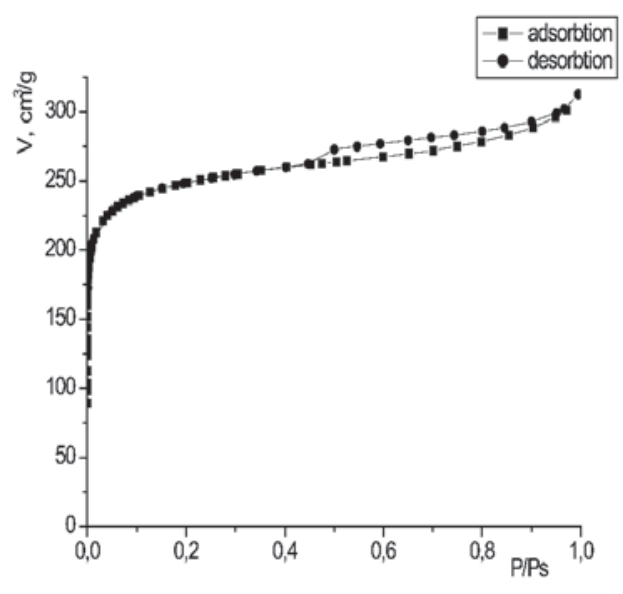

3

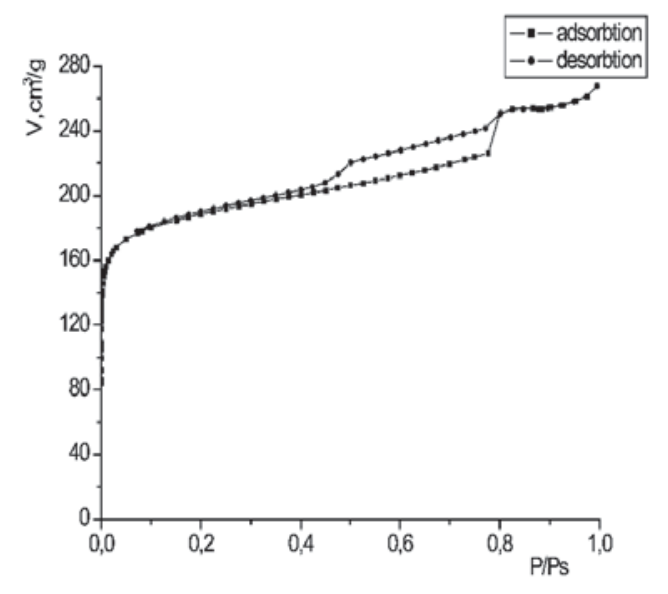

4

Figure 3. Adsorption-desorption isotherms of nitrogen (77 K) for activated carbons CAP (1), CAN-8 (2), CAS-23 (3) and BAU (4).

Geometric surface and structure parameters of studied activated carbons were determined from adsorptiondesorption isotherms of nitrogen using the BET equation and the method NLDFT ((Non-Local Density Functional Theory) [11]. The results are presented in Table 1.

Analysis of the results suggests that the most effective carbonic adsorbent for immobilization of investigated substances could be the activated carbon CAN-8, with the highest value of $\mathbf{S}_{\text {gem }}\left(1071 \mathrm{~m}^{2} / \mathrm{g}\right)$. But if we take into account the size of $B_{12}$ molecules $(1.83 \times 1.41 \times 1.14 \mathrm{~nm})$ and Congo red dye $(2.8 \times 1.1 \times 0.5 \mathrm{~nm})[10]$ then we can assume that predominantly the mesoporous structure of coal CAP $\left(\mathrm{V}_{\mathrm{me}}=0.239 \mathrm{~cm}^{3} / \mathrm{g}\right)$ will be the crucial feature in the immobilization of investigated substances.

Table 1

Structural parameters of activated carbons CAN-8, CAS-23, CAP and BAU

\begin{tabular}{|c|c|c|c|c|c|}
\hline AC sample & $\begin{array}{c}\mathrm{V}_{\mathrm{s}}, \\
\mathrm{cm}^{3} / \mathrm{g}\end{array}$ & $\begin{array}{l}\mathrm{W}_{01}, \\
\mathrm{~cm}^{3 / \mathrm{g}}\end{array}$ & $\begin{array}{l}S_{\text {geom, }} \\
\mathrm{m}^{2} / \mathrm{g}\end{array}$ & $\begin{array}{l}\text { Vme, } \\
\mathrm{cm}^{3} / \mathrm{g}\end{array}$ & $\begin{array}{c}\text { Vme/ } \\
\%\end{array}$ \\
\hline CAN-8 & 0,598 & 0,413 & 1071 & 0,185 & 30.9 \\
\hline CAS-23 & 0,484 & 0,376 & 945 & 0,108 & 22.3 \\
\hline CAP & 0,541 & 0,302 & 769 & 0,239 & 44.2 \\
\hline BAU & 0,41 & 0,28 & 713 & 0,13 & 31.7 \\
\hline
\end{tabular}

$\mathbf{V}_{\mathrm{s}}$ - sorption volume of pores; $\mathbf{W}_{\mathbf{0 1}}$ - micropores volume; $\mathbf{S}_{\text {geom }}$ - geometrical surface of pores; $\mathbf{V m e}$-mesopores volume.

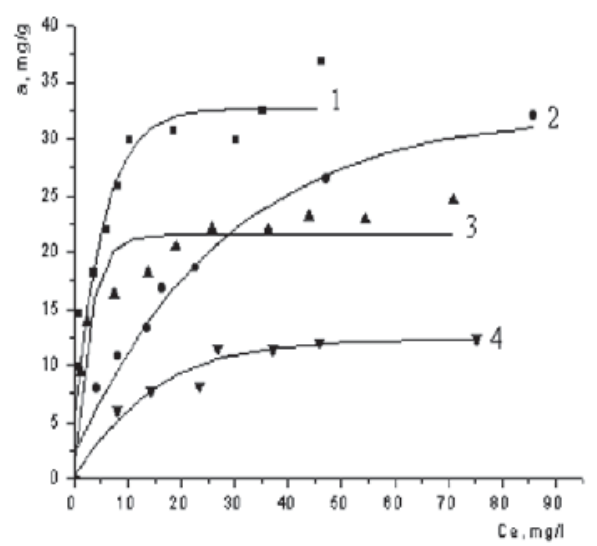

A

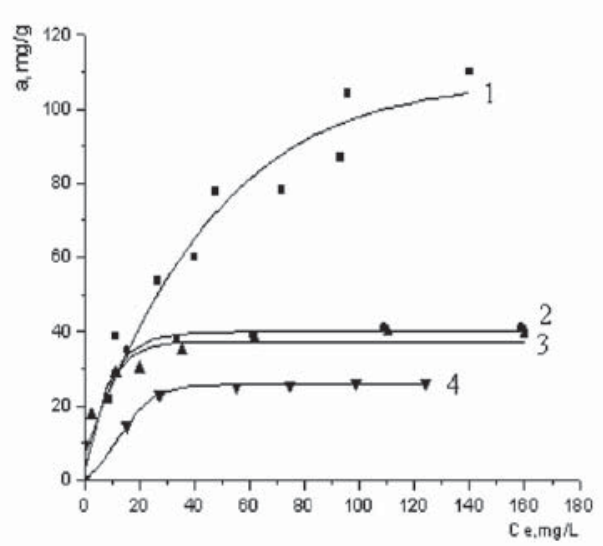

$\mathrm{B}$

Figure 4. Adsorption isotherms of vitamin $B_{12}$ (A) and Congo Red dye (B) on activated carbons CAP (1), CAN-8 (2), BAU (3) and CAS-23 (4). 
Absorption of studied substances was determined according to the equation (1):

$$
a=\frac{(\mathrm{Co}-\mathrm{Ce}) \mathrm{V}}{m},
$$

where: $a$-adsorption, $\mathrm{mg} / \mathrm{g} ; \mathrm{C}_{0}$ - initial solution concentration, $\mathrm{mg} / \mathrm{L} ; \mathrm{Ce}$ - equilibrium concentration, $\mathrm{mg} / \mathrm{L} ; \mathrm{V}$ - solution volume, $\mathrm{L} ; \mathrm{m}$ - sorbent quantity, $\mathrm{g}$.

Adsorption isotherms of Congo Red dye and vitamin $\mathrm{B}_{12}$ on investigated activated carbons are shown in Figure 4.

The results confirm the hypothesis of more effective activated carbon CAP at immobilizing investigated substances. This allows us to conclude that the determinant role in the adsorption of vitamin $\mathrm{B}_{12}$ and Congo Red dye was played by structural parameters of studied carbons, and especially the value of mesopores volume which is in direct correlation with the value of maximum adsorption (Figure 5).

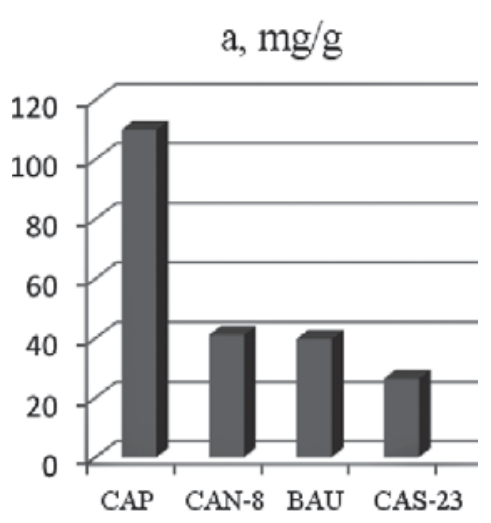

A $\mathrm{a}, \mathrm{mg} / \mathrm{g}$

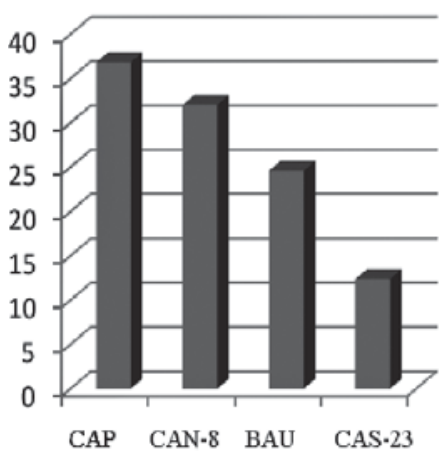

B

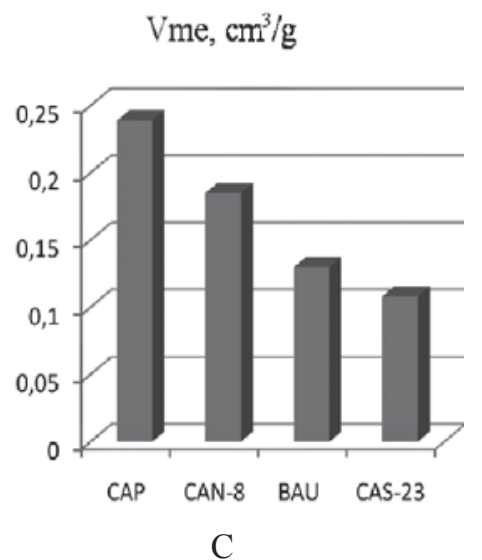

C

Figure 5. Correlation between the values of maximal adsorption of Congo Red dye (A), vitamin $B_{12}$ (B) and the values of mesopores volume $(C)$ of studied activated carbons.

Pore volume occupied by molecules of Congo Red dye and vitamin $\mathrm{B}_{12}$ in investigated activated carbon pores was determined from equation (2):

$$
\mathrm{V}_{\mathrm{S}}^{*}=a_{m} \cdot \mathrm{V}^{*},
$$

where: $\mathrm{V}_{\mathrm{S}}^{*}$ - pore volume occupied by molecules in the pores of activated carbon adsorbents, $\mathrm{cm}^{3} / \mathrm{g} ; a_{m}-\mathrm{maximal}$ adsorption value of adsorption on active carbons, mmol/g; $\mathrm{V}^{*}$ - molar volume of adsorbents calculated from the values of length and Van der Waals angles between molecules' atoms.

Values $\mathrm{V}^{*}$, calculated according to [10], are $2.94 \mathrm{~nm}^{3}$ for $\mathrm{B}_{12}$ and $1.54 \mathrm{~nm}^{3}$ for Congo Red. Table 2 presents the results of estimating the pore volume $\mathrm{V}^{*}$ occupied by molecules of investigated substances on investigated carbon samples and the rate of use of mesopores $\mathrm{G} \%$, calculated according to equation 3 .

$$
\mathrm{G} \%=\left(\mathrm{V}_{\mathrm{s}}^{*} / \mathrm{Vme}\right) \cdot 100
$$

Table 2

Pore volume $V_{\mathrm{S}}$ and the rate of use of mesopores G\% for activated carbons CAN-8, CAS-23, CAP and BAU

\begin{tabular}{|c|c|c|c|c|c|c|c|}
\hline \multirow{2}{*}{ AC sample } & \multirow{2}{*}{$\begin{array}{c}\mathrm{Vme}, \\
\mathrm{cm}^{3} / \mathrm{g}\end{array}$} & $\begin{array}{c}a_{m}, \\
\mathrm{mmol} / \mathrm{g}\end{array}$ & $\begin{array}{c}\mathrm{V}_{\mathrm{s}}^{*}, \\
\mathrm{~cm}^{3} / \mathrm{g}\end{array}$ & $\mathrm{G}, \%$ & $\begin{array}{c}a_{m}, \\
\mathrm{mmol} / \mathrm{g}\end{array}$ & $\begin{array}{c}\mathrm{V}_{\mathrm{S}}^{*}, \\
\mathrm{~cm}^{3} / \mathrm{g}\end{array}$ & $\mathrm{G}, \%$ \\
\hline $\mathrm{CAN}-8$ & 0,185 & 0,0236 & 0,0418 & 22,59 & 0,0574 & 0,0533 & 28,81 \\
\hline $\mathrm{CAS}-23$ & 0,108 & 0,0096 & 0,0170 & 15,74 & 0,0316 & 0,0293 & 27,13 \\
\hline CAP & 0,239 & 0,0295 & 0,0523 & 21,88 & 0,1579 & 0,1465 & 61,29 \\
\hline BAU & 0,13 & 0,0177 & 0,0314 & 24,15 & 0,0560 & 0,0519 & 39,92 \\
\hline
\end{tabular}

The obtained data show higher indices for mesopores use in the case of Congo Red dye, which is due to the smaller size of the dye molecule opposite the vitamin $\mathrm{B}_{12}$ molecule size.

There have been studies on the influence of increasing temperature and decreasing $\mathrm{pH}$ on the immobilization process of marker substances. Adsorption isotherms were determined for investigated substances at $\mathrm{t}=38^{\circ} \mathrm{C}$ and in solution with $\mathrm{pH} 2$. It was found that increase of temperature to $38^{\circ} \mathrm{C}$ and $\mathrm{pH}$ decrease to 2 is accompanied by an increase in the rate of immobilization of the dye Congo Red and vitamin $\mathrm{B}_{12}$ on average by $10 \%$ (Figure 6,7 ). 


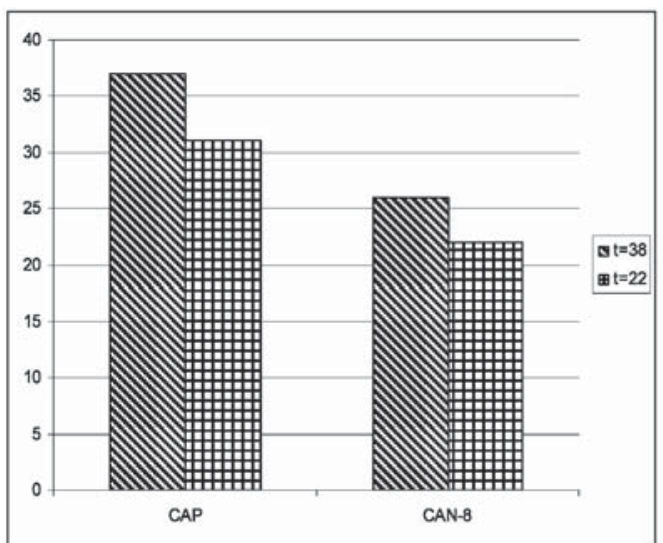

Figure 6. Influence of temperature on vitamin $B_{12}$ adsorption from aqueous solutions

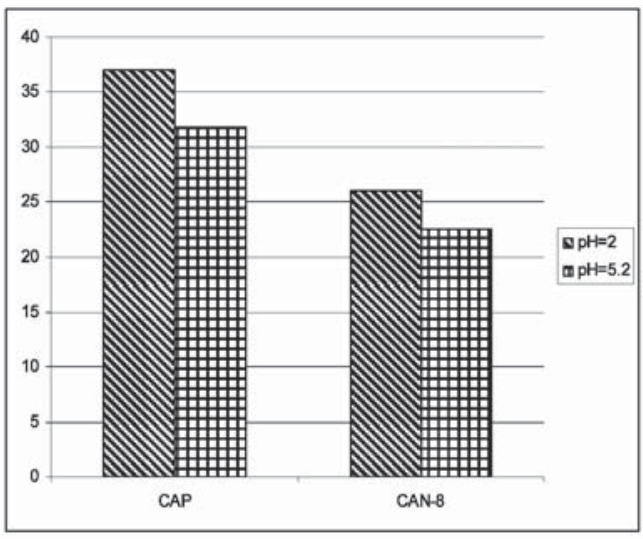

Figure 7. Influence of $\mathbf{p H}$ on vitamin $\mathrm{B}_{12}$ adsorption from aqueous solutions

\section{Conclusions}

1. It was established that the immobilization of the Congo Red dye and vitamin $\mathrm{B}_{12}$ depends directly on the structural parameters of activated carbons, in particular, the volume of mesopores, and the structure and molecular weight of the adsorbed substance. The adsorption highest values were recorded for activated carbons from plum stones, with a mesopores volume practically twice higher than of the other carbons.

2. Increase of temperature to $38^{\circ} \mathrm{C}$ and $\mathrm{pH}$ reduction to 2 probably enhances the diffusion of adsorbed molecules in the pores of the adsorbent, which increases adsorption with around $10 \%$.

\section{References}

[1]. Duca, Gh.; Scurlatov, Iu.; Misiti, A.; Macoveanu, M.; Surpățeanu, M. Ecological chemistry./In romanian. Bucharest: Matrix Rom., 1999, pp 305.

[2]. Negulescu, M.; Vaicum, L.; Pătru, C.; ş. a. Environment protection. /In Romanian. Bucharest, 1995 , pp 204.

[3]. Lupaşcu, T. Activated carbon from vegetal raw materials. Monograph/ In Romanian L.: ÎEP: Ştiinţa, Chişinău, 2004, pp 224.

[4]. Lupaşcu, T. Modern technologies for obtaining activated carbons and its use for the environment protection and human health. /In Romanian. Buletinul ASM, Seria ŞBCA, 2004, nr 1, pp 170-175.

[5]. Rodriguez-Reinoso, F.; Lopez-Gonzalez, I. Activated carbons from almond shells. Caracterization of the pore structure. Carbon, 1984, vol. 22, pp.13-18.

[6]. Lupaşcu, T.; Ciobanu, M.; Țîmbaliuc, N. Uze of oxidized activated carbon in water treatment processes. Environmental Engineering and Managament Journal. September, 2002. vol.1.№2, pp.169-176.

[7]. Lupaşcu, T.; Ciobanu, M.; Ţîmbaliuc, N. Adsorption of dyes and surfactants from aqueous solutions on activated carbons. /In Romanian. Journal of chemistry, 2007, v. 58, nr.10, pp. 905 -908.

[8]. Lupaşcu, T.; Ţîmbaliuc N. Elaboration of technological scheme of sewage treatment at the textile industries. / In romanian. Materials of the Conference INECO 15 years "Ecology and environment - research, implementation and management". 29 December, Chisinau, 2006, pp.201-204.

[9]. Shen, W.Z.; Zheng, J.T.; Zhang, Y.L.; Wang, J.G.; Qin Z.F. The effect of pore structure of activated carbon on the adsorption of Congo red and vitamin B12. Studies in Surface Science and Catalysis. Volume 146, 2003, pp 779-782.

[10]. Wenzhong Shen, Jingtang Zheng, Zhangfeng Qin, Jianguo Wang, Yihong Liu. Preparation of mesoporous activated carbon fiber by steam activation in the presence of cerium oxide and its adsorption of Congo red and Vitamin B12 from solution. Journal of Materials Science, vol. 39, no.13, 2004 July, pp. 4693 - 4696.

[11]. AUTOSORB AS-1. AS1Win. GAS SORPTION SYSTEM. OPERATION MANUAL. Firmware: ver 2.55. AS1Win Software: ver 2.0 and newer. Quantachrome Instruments, 2008. 